This is an earlier version of the paper published in the Journal of

Criminological Research, Policy and Practice, March 2016, Volume 2, Issue 1, pp. 54-66.

The Effectiveness and Impact of the Child Protection and Criminal Justice Systems on Victims of Intrafamilial Child Sexual Abuse

\title{
Anna Gekoski
}

Corresponding author. Forensic Psychological Services (FPS), Middlesex University, The Burroughs, London, NW4 4BT, UK. Email: annagekoski@hotmail.com Tel: +442084115555 Miranda A.H. Horvath

Forensic Psychological Services (FPS), Middlesex University, The Burroughs, London, NW4 4BT, UK. Email: m.horvath@mdx.ac.uk

\section{Julia C. Davidson}

Centre for Abuse and Trauma Studies, Middlesex University, The Burroughs, London, NW4 4BT,UK.Email:j.davidson@mdx.ac.uk

\section{Acknowledgements}

The authors are grateful to the Office of the Children's Commissioner for England, who funded the Rapid Evidence Assessment (REA) on which this paper is based. The authors would also like to thank colleagues Julie Grove-Hills and Clare Choak for their hard work on the REA, and Antonia Bilfulco and Julie Grove-Hills for their work on previous research on police practice with victims of child sexual abuse, which this work draws on. 


\begin{abstract}
Purpose: This paper reports on the findings from a study commissioned by the Office of the Children's Commissioner (OCC) in England, concerning intrafamilial child sexual abuse (IFCSA)/incest. Specifically, it aims to explore the evidence about child protection and criminal justice responses to victims of IFCSA in the UK and where the gaps in these approaches lie.
\end{abstract}

Design: A Rapid Evidence Assessment (REA) was used, the function of which is to: search the literature as comprehensively as possible within given time constraints; collate descriptive outlines of the available evidence on a topic and critically appraise it; sift out studies of poor quality; and provide an overview of the evidence. Over 57,000 documents were scanned, and 296 ultimately systematically analysed.

Findings: It was found that children may be re-victimised by various aspects of 'the system' and professionals within it, including social workers, police officers, and lawyers.

Limitations: An REA is not a full systematic review, differing in the scope and depth of the searches and depending almost exclusively on electronic databases, not accompanied by searching journals by hand.

Value: The findings of this research provide the evidence-base for a new two-year inquiry into the subject of IFCSA by the OCC.

Implications for practice: Victims of IFCSA may benefit from the following changes:

- the prioritising of children's needs over bureaucratic demands;

- better multi-agency working;

- the consistent use of ABE interviews in child-friendly environments;

- the increased use of special measures in court; and

- the piloting of specialist sexual offence courts. 
Key words: child sexual abuse; intrafamilial; incest; child protection; criminal justice; secondary victimisation

\section{Introduction}

Research suggests that child sexual abuse (CSA) 'is a global problem of considerable extent' (Stoltenborgh, IJzendoorn, Euser, \& Bakermans-Kranenburg, 2011, p.79). Furthermore, although the media might have us believe otherwise (Greer, 2007), the vast majority of CSA is committed by someone known to the child (Radford, Corral, Bradley, Fisher, Bassett, Howat, \& Collishaw, 2011). Yet the sexual abuse of children within a family environment referred to as intrafamilial child sexual abuse (IFCSA) or incest - may often go unreported, particularly in comparison to CSA by strangers, also known as extrafamilial child sexual abuse (EFCSA) (Jensen, Gulbrandsen, Mossige, Reichelt, \& Tjersland, 2005).

However, even when IFCSA is reported, there are then frequently further problems, as the harm caused by the primary abuse may be exacerbated by negative experiences and interactions with the child protection system (CPS) and criminal justice system (CJS) (e.g. Plotnikoff \& Woolfson, 2009). This may give rise to feelings of secondary victimisation, which 'occurs when victims of crime feel they have been subjected to inadequate, insensitive or inappropriate treatment, attitudes, behaviour, responses and/or practices by criminal justice and social agencies, which compound their original trauma' (Gekoski, Adler, \& Gray, 2013, p.307).

The Office of the Children's Commissioner (OCC) in England recently pledged to carry out a new two-year inquiry into the subject of IFCSA. The authors of this paper were commissioned to provide the evidence-base for this inquiry, using a Rapid Evidence Assessment (REA). For the purposes of this work, a 'child' is defined as 'any person under 18 years of age', in accordance with the United Nations Convention on the Rights of the 
Child (UNCRC) 1989. And the term IFCSA is defined as 'child sexual abuse perpetrated by a family member or that takes place within a family context or environment, whether or not by a family member.' This paper explores the effectiveness and impact of the CPS and CJS on victims of IFCSA in the UK, focusing on the following research question: What is known from the evidence about child protection and other action in response to victims of IFCSA? Where are the gaps in these approaches?

\section{Method}

\section{Design}

We adopted a question-led adapted REA, the functions of which are to: search the electronic and print literature as comprehensively as possible within the constraints of a policy or practice timetable; collate descriptive outlines of the available evidence on a topic; critically appraise the evidence; sift out studies of poor quality; and provide an overview of what the evidence is saying (Davies, 2003). REA's have been widely used in recent years on a wide range of policy relevant issues (e.g. Brayley, Cockbain, \& Gibson, 2014; Horvath, Alys, Massey, Pina, Scally, \& Adler, 2013).

\section{Procedure}

Inclusion/exclusion criteria for material and generation of search terms

The initial step in identifying the relevant material was to set the inclusion/exclusion criteria for the literature ${ }^{1}$. The key criteria for the inclusion of material were:

- $\quad$ studies published from $1^{\text {st }}$ January 1999 to $1^{\text {st }}$ March 2014;

- $\quad$ studies focused on children (but including retrospective studies with adults);

- $\quad$ studies focused on IFCSA;

\footnotetext{
${ }^{1}$ These were set by the funder.
} 
- publically available academic research, non-academic research, reports, policy documents, reviews, and meta-analyses;

- English language publications;

- all jurisdictions; and

- all research methods (i.e. all relevant studies regardless of the methodological approach adopted).

Search terms were subsequently developed, ensuring scope and rigour. From these search terms, nine separate search strings were generated, made up of various combinations of the terms.

\section{Literature searching}

The relevant literature was identified through three main methods: (i) systematic searches for relevant studies and literature across high priority academic databases (PsycINFO, ISI Web of Science (WOS), International Bibliography of the Social Sciences (IBSS), and LexisNexis); (ii) an online search for Grey Literature (e.g. Barnardos, NSPCC, Nuffield, and Leverhulme); and (iii) requesting relevant material through a Call for Papers (sent to networks of researchers and practitioners primarily in the UK). Endnote Software was used to store search results at every stage.

\section{Data abstraction}

The first stage of searching identified 57,226 references, each of which was then screened in more depth. First, the titles and abstracts/executive summaries were reviewed and included or excluded according to the aforementioned criteria. Where possible, full text articles were then obtained and read for all material that fit the inclusion criteria $(\mathrm{N}=660)$. At this stage a further 364 references were excluded, leaving a total of 296 references for the final analysis. Key 
information from each piece of material (e.g. author(s), title, date of publication, type of source, country, and method) was then extracted onto a specially designed Excel spreadsheet.

\section{Weight of Evidence (WoE) coding}

Each reference was then evaluated using an adapted 'Weight of Evidence' (WoE) approach, in which the quality and relevance of the literature was assessed and given a strength rating. This approach was developed by the EPPI-Centre (Evidence for Policy and Practice Information and Co-ordinating Centre; Gough, 2007) and can be used for both quantitative and qualitative research. Given the tight timeframe for this piece of work, the EPPI-Centre's approach was slightly simplified, with each study weighted according to three (as opposed to five) dimensions.

(A) Taking into account all of the quality assessment issues, can the study findings be trusted in answering all of the study question(s)?

(B) How appropriate is the research design and analysis for addressing the question, or sub-questions, of this review?

(C) How relevant is the particular focus of the study (including conceptual focus, context, sample and measures) for addressing the questions of this review?

These judgements were then combined into a final dimension, which provided the overall WoE judgement (high, medium, or low). Of the 296 papers included in the final analysis, 55 fell into the 'low' WoE category, 116 into the 'medium', and 125 into the 'high'.

\section{Data synthesis}

To produce the final report, the data was synthesised. This was done by identifying, exploring, integrating, and writing-up patterns and themes in the data. Finally, the synthesis was revisited to check for quality, sensitivity, coherence, and relevance.

\section{Limitations}


Several methodological limitations should be noted. To begin with, an REA is not a full systematic review, differing in the scope and depth of its searches. For example, searching for a full systematic review often takes more than three months, while the searches for this report took less than three weeks. The searches conducted also depended almost exclusively on electronic databases and were not accompanied by searching key journals by hand. The fact that initial studies were excluded based on the abstract alone is also a potential weakness, as it may have led to some studies with a minor focus on IFCSA being excluded.

\section{Results}

The findings are organised thematically (with superordinate themes and subthemes), focusing on what existing research can tell us about the effectiveness and impact of the CPS and CJS in cases of IFCSA. Superordinate themes are organised according to the three main UK agencies that child victims come into contact with: (1) the child protection system; (2) the police; and (3) and the court/legal system. It should be noted that there is little research of high quality (as measured against the WoE approach) that makes direct reference to IFCSA and even less that directly considers children's experiences. In the absence of a shared definition of IFCSA in the literature, the research drawn on is broader in focus than the definition laid out in the introduction. For example, some included studies consider IFCSA alongside other types of abuse; fail to make distinctions between IF- and EFCSA; and/or use the general term CSA throughout.

\section{The child protection system (CPS)}

Care proceedings for alleged sexual abuse are often unsuccessful in comparison to physical abuse or neglect (Bacon, 2008), with only around 5\% of all children on child protection 
registers ${ }^{2}$ or the subject of a child protection plan in the UK being in a category that includes sexual abuse (NSPCC, 2014). However, being subject to a child protection plan brings problems in itself (Oliver, 2010). In their evaluation of 65 serious case reviews (including those relating to CSA) Ofsted (2011) identified five key areas of concern: (i) the child not being seen often enough by professionals or being asked about their opinions and feelings; (ii) agencies not listening to adults speaking on the child's behalf; (iii) parents/carers stopping professionals having contact with the child; (iv) professionals being overly focused on the needs of parents; and (v) agencies not properly interpreting findings in order to protect the child. The research explored below indicates that this may be due to a culture which has become increasingly dominated by targets, timescales, and assessments.

\subsection{Social workers are overburdened by bureaucratic demands and targets, at the expense of forming good relationships with, listening to, and protecting children}

Social workers have identified numerous problems in working with cases of CSA. They may, for example, experience negative societal reactions - such as accusations of subjectivity, encouraging false allegations, and creating secrecy - which may lead to a reluctance to work on such cases (Bacon, 2008). Social workers also report excessive expectations by managers and unrealistic government targets, concerns about how to focus on the child while managing relationships with parents, lack of necessary resources, pressurised decision-making, and insufficient information (Platt, 2006).

Recently, Professor Eileen Munro carried out a series of reports (2010, 2011a, 2011b) in the UK 'investigating what helps professionals make the best judgements they can to protect a vulnerable child?' (Munro, 2011b, p.6). These reports were informed by the views of CPS professionals, including social workers, many of whom felt that their professional

\footnotetext{
${ }^{2}$ Child protection plans were abolished in England in 2008 - but not Northern Ireland, Scotland, and Wales replaced by information collected on children who are subject to child protection plans.
} 
judgement was no longer 'valued, developed, rewarded or motivated in the system of child protection' (p.30), feeling that it had been replaced with professional principles, guidance, timescales, and targets.

In light of such responses, Munro (2010) argued that although recent new reforms in the CPS are individually well intentioned, taken together they may be detrimental, creating 'a risk that they [the child] will be deprived of the care and respect that they deserve' (p.18). A similar picture emerged in Munro (2011), where findings included: timescales being too prescriptive at the expense of quality of assessment, the inspection process concentrating on process as opposed to effectiveness, and the key importance of front-line professionals developing trusting relationships with children to find out how they want to be helped.

\subsection{Children's experiences of the child protection system (CPS) are largely, although not} entirely, negative

Although there is a lack of research with victims of CSA regarding their experience of the CPS - with many studies relying on adult retrospective samples - most of what there is supports the above findings. A notable exception is an early study (based on interviews with 35 children and their carers concerning social workers' responses to CSA) in which most children thought their social workers were helpful and likable (Prior, Lynch, \& Glaser, 1999). Specifically, they spoke of feeling listened to; being given information in an honest and child-appropriate way; and social workers being sympathetic, sensitive, accessible, and consistent.

However, just over a decade (and many reforms) later, a more negative picture was presented by a study which explored children's relationships with social workers (Oliver, 2010). Children reported that social workers were difficult to get in touch with, hard to confide in, frequently changed, and often failed to turn up for meetings. A digest of 13 years 
of work consulting vulnerable children about safeguarding issues by the Children's Rights Director for England (Morgan, 2014) supported some of these findings, with children reporting that social workers were difficult to get hold of or broke their promises, were constantly changed, and their decisions overruled by financial concerns. Another recent study, based on interviews with 26 children with child protection plans (including for CSA), found negative experiences with social workers to include intrusion, family stress, and stigma (Cossar et al., 2011).

Reflecting on their experiences of the CPS more generally, children spoke of not seeing their child protection plans, not knowing how to make their views heard in meetings, not being able to see reports on them (Cossar et al., 2011); finding the system confusing and distressing, wanting a say in decisions about being placed away from home (Oliver, 2010); finding the CPS confusing and lacking in transparency, wanting to be seen separately from their parents, and a lack of information, honesty, and support (Munro, 2010, 2011a, 2011b).

Conversely, what is valued is: practical help, school liaison, talking about their problems, help with family relationships (Cossar et al. (2011); consistent help from the same social worker, being treated with respect, having services that are not taken away as soon as the crisis passes (Munro, 2010, 2011a, 2011b); honesty, a say in important decisions, being kept informed (Morgan, 2014); and having social work support that is responsive, flexible, individual, personalised, participative, and respectful of their needs and wishes (Oliver, 2010).

The research above seems to demonstrate little positive progress in terms of the child's experience of the CPS over the past 15 years. In fact, the reverse may be true, given that children reported the most positive experiences in the earliest study considered here (Prior et al., 1999). This apparently retrograde step may be attributed to the increasing bureaucratic demands as described by social workers in Section 1.1. 


\subsection{There are some pockets of good child protection practice in the UK that are based on}

principles of multi-agency working

This review did, however, find some examples of good practice in the UK, although there is currently a lack of evaluations of such programmes. A Home Office (2013) project that sought to develop a UK-wide picture of innovative multi-agency models found numerous systems in place, including: Front Door, Access, Triage, Central Duty Team, Multi-Agency Referral Unit, and Multi-Agency Safeguarding Hub and Joint Action Teams. These are 'based upon three common principles: information sharing, joint decision making and coordinated intervention' (p.4).

For example, the Multi-Agency Safeguarding Hub (MASH) programme aims to identify children at risk earlier and share information among professionals from the police, social care, education, probation, and health services. In Devon, where the programme started, the council observes that such multi-agency working ensures that children's needs are identified and addressed quickly, reduces the number of professionals involved, avoids unnecessary visits, simplifies processes, and improves communication between professionals (Devon County Council, n.d.).

The Triangle project in Brighton works with children and young people to provide 'a range of services including specialist expert witness reports, forensic interviewing, intermediary services, advocacy and support' (Triangle, n.d). For example, forensic interviews are conducted using advanced technology in child-friendly facilities (such as a three camera digital interview suite inside a playroom), and reports for the courts can be provided by multi-disciplinary teams, including psychologists, therapists, neurologists, social workers, nurses, teachers, intermediaries, and interpreters.

The 'systemic unit' model (also known as the Hackney Model or Reclaiming Social 
Work) has been positively evaluated as an approach to delivering Children's Social Services (Forrester, Westlake, McCann, Thurnham, Shefer, Glynn, \& Killian, 2013). In this model, cases are allocated to a consultant social worker who manages a small team of professionals who work jointly with the family or child. It has been found that, in comparison to conventional models, in systemic units: more time is spent with families and children, assessments are of higher quality, skill levels are consistently high, and more intensive help is provided for families (Forrester et al., 2013). These examples of good practice have commonalities with international models of child protection, as considered in the discussion.

\section{The police}

When a complaint of IFCSA is made to the police, they have a duty to investigate the allegation. In order to determine whether a crime has been committed and, if so, who is responsible, they may: conduct medical examinations; take statements from, and conduct interviews with, victims, witnesses, and suspects; and prepare files to be sent to the Crown Prosecution Service. However, the literature explored here found concerns about how the police treat victims, their investigate methods, and how they dispose of cases.

\subsection{Victims of (IF)CSA report a lack of information and investigative effort by the police}

In recent times the role of the police in the UK has been explicitly extended to encompass more victim centred priorities. However, findings from the British Crime Survey show that a sizable minority of victims are still dissatisfied with how they are treated by the police, who may show insufficient interest in their case, be impolite, slow to respond, or not provide them with information (Allen, Edmonds, Patterson, \& Smith, 2006).

Although the above findings relate to adult victims, research has found similar problems in cases involving CSA (e.g. McDonald \& Tijierino, 2013; Ben-Arieh \& Windman, 
2007). For example, in Northern Ireland, a major concern expressed by parents/carers of young witnesses (including victims of CSA) was a lack of information from the police (Hayes, Bunting, Lazenbatt, Carr, \& Duffy, 2011). As one parent said: 'The police ... failed to return our calls ... When they did make contact her [the police officer's] attitude was disgusting - she just didn't seem interested and gave us no information at all' (p.36).

\subsection{Only a minority of alleged cases of (IF)CSA are classified as detected crimes by the} police

Davidson and Bilfulco (2009) found that only a minority of cases of IFCSA are classified as detected crimes by the police. Data from case files and interviews with child protection police officers revealed that this may be due to: problems with multi-agency working; high staff turnover; inexperienced social workers and child protection officers; and problems with the Crown Prosecution Service, including slow responses, delays in making decisions, lack of communication, and low confidence in junior lawyers. The authors concluded that, despite many dedicated police child protection officers, the investigative system is often failing victims.

To explore reasons for high Crown Prosecution Service discontinuance rates, low conviction rates, and reflect on the experience of the child, Davidson, Bilfulco, Grove-Hills and Chan (2012) explored Metropolitan Police investigative practice with victims of IFCSA. They found problematic issues to include time constraints, a lack of child consultation, insufficient use of intermediaries, and high police staff turnover in specialist units. Particular problems were found with police interviewing practices with victims, as discussed below.

\subsection{The police do not always adequately follow guidelines for Achieving Best Evidence} (ABE) interviews 
Investigative interviews in which children give their account of the alleged abuse usually constitute the main evidence for referral to the Crown Prosecution Service, as other corroborative evidence is often lacking (Guðbrandsson, 2010). In the UK, Achieving Best Evidence (ABE) guidance sets out a four stage interview process, which includes: building rapport, free narrative, questioning, and closing (Robinson, 2008a). It is advised that interviews be conducted jointly by police officers and social workers, although in practice this rarely happens (Robinson, 2008b).

A crime is more likely to be classified as detected when an ABE interview has been carried out with a victim of CSA (Davidson \& Bilfulco, 2009). Yet, despite this, they are not used properly (or at all) in the majority of cases. Specific problems include: interviews beginning with utility questions rather than rapport building, the interviewer jumping in with particular questions too quickly (Westcott \& Kynan, 2006); too many leading and/or accusatory questions, children being barraged with questions, the use of complex language, formulaic routines that fail to account for children's differences, not allowing free narrative accounts (Robinson, 2008b); time constraints, poor interview environments, a lack of child consultation, and intermediaries not being used (Davidson et al., 2012).

Difficulties with police training have also been reported. Davidson and Bilfulco (2009) found that while all child protection police officers sampled had received ABE training, this was often too short, with a lack of 'refresher' training. In their survey of 91 police officers in Scotland, La Rooy, Lamb, and Memon (2011) also expressed concern regarding the failure to conduct practice interviews, use open-ended prompts, record interviews, and receive feedback about interview quality.

More recently, the increased use of video (as opposed to audio) taped interviews has brought extra benefits, including the observation of body language, making the process more transparent, and having a better interview record (Richards, Morris, Richards, \& Siddall, 
2007). Yet it has been found that (unless the offence is particularly serious or the child very young) video-recorded interviews are not often used, with officers tending to take a written statement (HMCPSI \& HMIC, 2012).

Inadequately conducted interviews may have numerous detrimental outcomes, including: eliciting false allegations, affecting children badly (Wood \& Garven, 2000); and negatively impacting on conviction rates (Robinson, 2008b). This underscores the importance of professionals following ABE interviewing guidelines. However, the frequent failure to follow best practice guidelines runs throughout the CJS as discussed below.

\section{The legal/court system}

Most work concerning the experiences of victims of IFCSA in the CJS considers the legal/court process, even though the vast majority of cases do not progress to this stage. However, when such cases do reach court, there are often multiple problems for children, both pre and during trial, which may re-victimise them, having potentially devastating shortand long-term effects.

\subsection{Victims of (IF)CSA are often not given adequate support and/or court familiarisation visits pre-trial}

Pre-trial issues include not all children being given court familiarisation visits and a lack of support (e.g. HMCPSI \& HMIC, 2012). In a study of 50 young people (32 of whom had been victims of sexual offences) about their experiences of being a witness in court, just under half received a pre-trial court familiarisation visit and 14 had no contact with a supporter before the trial (Plotnikoff \& Woolfson, 2004).

A subsequent piece of research by the same authors (Plotnikoff \& Woolfson, 2009), with a larger sample size of 182 children, found that little had changed over the intervening five years, with almost exactly the same percentage of children (half) having had a pre-trial 
court familiarisation visit. In some instances, things had become worse, with just under half (44\%) of children having no contact with a supporter before the trial.

In Northern Ireland, interviews with 37 children (including victims of CSA) about their experience of pre-trial support and of giving evidence in court also found 'little in the way of pre-trial assistance' (Hayes et al., 2011, p.64), with just over half (54\%) having pretrial contact with a supporter from the NSPCC Young Witness Service and just under half (49\%) having a court familiarisation visit. Yet (as found by the previous two studies) when support was provided it was rated highly, with $85 \%$ of children saying the supporter had made a significant difference or made it possible for them to go to court at all.

\subsection{Long waiting times to go to trial may cause or exacerbate mental health problems in victims of (IF)CSA}

Long waiting times to go to trial have been found to cause and/or exacerbate psychological and mental health problems (e.g. HMCPSI \& HMIC, 2012). In Ireland, 43 victims of CSA completed the Criminal Justice System Questionnaire, which assesses satisfaction with the system (Connon et al., 2011). Children found nine aspects of the system particularly upsetting, with the impact of waiting for court coming fourth. The children in Plotnikoff and Woolfson's (2004) study waited, on average, 11.6 months for their case to reach court. During this time 35 described themselves as very nervous or scared, nine as intimidated, and 20 spoke of symptoms of anxiety; a positive correlation was noted between pre-trial anxiety and not being kept informed about the case. The parents and carers of victims in the study by Hayes et al. (2011) also described how their children were worried, stressed, and/or intimidated by the defendant or the defendant's supporters while waiting (an average of 18.1 months) to go to court. 


\subsection{Special measures available to help victims of (IF)CSA give best evidence are often not utilised}

When the trial date arrives, there are arguably even more serious problems encountered by victims. The Youth Justice and Criminal Evidence Act 1999 introduced a raft of 'special measures' to help children (and other vulnerable and intimidated witnesses) to give best evidence in the UK. These measures include: screens to shield the witness from the accused in court, evidence given by live link rather than in the courtroom, the courtroom being cleared so evidence can be given in private, the removal of wigs and gowns, video-recorded evidence-in-chief, video-recorded cross-examination or re-examination pre-trial, examination through an intermediary, and the use of communication aids. Such measures must be approved by a judge.

Unfortunately it has been found that special measures may not always be discussed, applied for, or offered as an option. A quarter of the 24 parents interviewed by Hayes et al. (2011) said that they had not been consulted about special measures for their children. Similarly, there are often assumptions made about the best methods for children to give evidence (HMCPSI \& HMIC, 2012), with children in Plotnikoff and Woolfson's (2004) study speaking of a lack of choice in this area.

When special measures are implemented with victims of CSA the outcomes tend to be very positive. This is particularly the case with measures that allow evidence to be given outside of the courtroom, such as video-recorded evidence-in-chief. For example, Plotnikoff and Woolfson (2009) found that of the 172 children in their study who gave evidence, 55\% had made a visually-recorded statement and, of these, 95\% used it as their evidence-in-chief, with $85 \%$ saying it was helpful.

Similar results have been found for giving evidence via live link, either in a separate room in the courthouse or a remote location. For example, a NSPCC study found that using a 
remote live link reduced stress on children (McNamee, Molyneaux, \& Geraghty, 2012). This makes court proceedings more likely to go ahead and children able to complete their evidence; victims of CSA may particularly benefit from the live link, as being in the witness box may be especially intimidating, embarrassing, and stressful for them (McNamee et al. 2012).

As noted by Cooper (2011), pre-trial video-recorded cross-examination or reexamination was not implemented along with other special measures. However, in 2013, a pilot scheme to trial the so-called 'full Pigot' in courts in Leeds, Liverpool, and Kingstonupon-Thames, was introduced. Given the distress caused by live cross-examination, as discussed below, this measure could potentially dramatically reduce secondary victimisation.

\subsection{Children are often subjected to aggressive cross-examination techniques by the defence, which can leave them re-traumatised}

The cross-examination of victims of CSA appears to be particularly problematic. Participants in Connon et al.'s (2011) research reported the defence barrister to be the most upsetting aspect of the system. Analysing the cross-examination of victims of CSA, Westcott and Page (2002) found that children may be painted as 'unchildlike', 'less than innocent', 'the aggressor', and 'poor witnesses'. In Plotnikoff and Woolfson's (2009) study, children described lawyers as aggressive, cross, rude and sarcastic; had problems understanding questions, finding them too complex or fast; and were asked repetitive questions, talked over, and accused of lying. Similarly, two thirds of the children in the study by Hayes et al. (2011) said they felt nervous, upset, tearful, scared, and distressed while being cross-examined. Children described questions as long, complex, incomprehensible, and repetitive; lawyers as rude and sarcastic; and the majority reported being called a liar.

Parents and carers supported these views, speaking of 'inappropriate and 
unnecessarily harsh questioning on the part of the defence lawyer' who 'was described as shouting and hectoring their child with little intervention from the court' (Hayes et al., 2011, p.68). Research by Davis, Hoyano, Keenan, Maitland, and Morgan (1999) also found that, while prosecutors felt the need to rely upon the judge to intervene if cross-examination was intimidating or unfair, many judges were reluctant to do so.

Sadly, such undermining, bullying, and aggressive cross-examination tactics are inherent to the adversarial system of justice, as the purpose of cross-examination is to undermine the witness's testimony, rather than to obtain the child's best evidence (Cooper, 2011). Yet this process is in direct violation of the principles involved in eliciting the most complete and accurate evidence from children (Zajac et al., 2012). Thus, it appears that:

'Despite a network of policies and procedures intended to facilitate children's evidence, only a handful of young witnesses in this study gave evidence in anything approaching the optimum circumstances. Their experiences reveal a chasm - an implementation gap - between policy objectives and actual delivery around the country’ (Plotnikoff \& Woolfson, 2004, p.8).

\section{Discussion}

The inescapable conclusion of the above research is that, with some exceptions, victims of CSA are being let down by the CPS and CJS in the UK. All too often such victims - already traumatised by the primary offence - are then re-traumatised by the very system that is there to investigate, corroborate, and punish the initial abuse (Anderson et al., 2002). This may cause adverse, and long-term, effects on children's mental health, education, and willingness to engage with the legal process in the future (Zajac et al., 2012). The authors thus concur with Munro's $(2010,2011 \mathrm{a}, 2011 \mathrm{~b})$ conclusion that to protect the welfare of children, as well as to get best evidence and secure convictions, children's feelings and experiences need to be 
taken into account. It is suggested that elements from international models of child protection and criminal justice might be drawn on to help build a more child-friendly system.

\section{The CPS: Multi-agency working in child-friendly environments}

Policy and legislation focusing upon the safeguarding of children in the UK has emphasised the importance of multi-agency working (e.g. Every Child Matters, 2003; Working Together, 2013) and, as discussed in Section 1.3, there are increasing examples of this across the UK. In the US, however, such multi-agency working has been common practice since the 1980s, where Children's Advocacy Centres (CACs) were developed in response to criticisms that interventions in child abuse could be re-victimising (Jackson, 2004).

In CACs, multi-disciplinary teams - made up of professionals from law enforcement, medicine, mental health, the legal profession, child protection, and victim advocacy - provide forensic interviews, victim support, case reviews and tracking, all in one place (Cronch, Viljoen, \& Hansen, 2005). This minimises the repeated interviewing of children by different professionals in different settings, which can lead to distortions in reporting, distress, and self-contradiction. Multi-agency working may also strengthen legal cases, with an association between the increased use of CACs and felony prosecutions having been found (Miller \& Rubin, 2009).

One of the key features of CACs are their child-friendly design, with developmentally-appropriate play areas, accommodations for children with special needs, decor that recognises diverse cultures, private interview rooms, and staff or volunteers to provide support (Cross, Jones, Walsh, Simone, \& Kolko, 2007). Using CACs as a model, the Children's House (Barnahus) was developed in Iceland, Norway, and Sweden, providing multi-disciplinary services, particularly in respect of investigative interviews (Guðbrandsson, 2010). These facilities are located in residential areas and have an environment designed to make the child feel comfortable and less anxious. Similarly, in Canada, the Gatehouse 
Investigative Programme provides a 24/7 service where child welfare workers and police officers work together with children in a neutral and child-friendly location (The Gatehouse Investigative Programme, 2012).

Cross et al. (2007) compared CAC to non-CAC communities, finding that police involvement, multi-agency interviews, case reviews, joint police/CPS investigations, and taping of interviews were all significantly more likely to occur in CACs. Furthermore, $85 \%$ of CAC interviews took place in child-friendly locations while comparison interviews took place in (e.g.) child protective services offices or police facilities, which are often not childfriendly and may be associated with criminals and exacerbate children's anxiety and feelings of guilt (Guðbrandsson, 2010). While Guðbrandsson (2010) notes that in the Children's House model, higher rates of parent, caregiver, and child satisfaction have been found, with children reporting low levels of anxiety during the investigation, in comparison to children interviewed elsewhere.

\section{The CJS: Sexual Offence Courts}

Booth and Carrington (2007) observe that 'perhaps one of the most interesting developments in the administration of criminal justice is the proposal to specialise courts to hear matters relating specifically to sexual assault matters and sexual violence' (p.408). Such courts have been trialled and implemented in various jurisdictions, including the USA, Australia, Canada, the UK, and South Africa. In the UK there are now over 140 Specialist Domestic Violence Courts, in which the prosecutor, magistrates/district judge, and legal advisor all have special expertise in such cases. Particular attention is also given to the victim's court experience, such as a separate waiting area, facilities, and entrance/exit to the courthouse, so that they do not encounter the defendant; in certain circumstances, evidence can also be given by a live television link (Bedfordshire Domestic \& Sexual Abuse Partnership, n.d.).

In addition to Domestic Violence Courts, some states in the US have various other 
specialist 'problem solving courts'. In New York, the first Sexual Offence Court was introduced in 2005 and, by August 2014, there were seven operating state-wide, which had heard 4,587 cases relating to both adult and child victims (NYCOURTS.GOV, n.d.). Such courts provide: sites where police officers, doctors, and child abuse services work together to reduce the number of interviews children have; crisis intervention; legal and social service advocacy; long-term counselling; assistance in securing medical, financial, and housing services; help with food and transportation; and assistance with protective orders (Thomforde-Hauser \& Grant, 2010).

In South Africa sexual offences courts were established in 1999 but, despite being considered a success - increasing conviction rates and decreasing turnaround time - most were abolished due to lack of training, space, and budget (SAFLII, 2013). However, in 2013 an advisory task team recommended their re-introduction (Mattso, 2013). Furthermore, in recognition that 'the generalist court system used in dealing with child sexual violence was hostile and causing further traumatisation of child victims' (p.19), it was recommended that 'a feeding scheme for child witnesses must be investigated for possible introduction in these courts' (Mattso, 2013, p.15). It was proposed that such courts include: case management to reduce delays and arrange pre-trial issues; a courtroom with CCTV, sound equipment and/or one-way glass; a special room for victims to testify in; a private waiting room/play area for victims and families; victim support services; an allocated social worker and court clerk; specially trained prosecutors and interpreters; a court preparation and debriefing programme for victims/witnesses; and the use of expert reports.

\section{Conclusions}

By providing child-friendly environments in which victims and multi-agency teams can work together, and establishing legal systems in which secondary victimisation is minimised, the 
child protection and criminal justice models explored above strive to put children's voices and wellbeing at the heart of the system. It is suggested that the UK both incorporate elements from such international models and build on existing systems of good practice, with the aim of significantly improving the experiences of victims of IFCSA.

\section{References}

Allen, J., Edmonds, S., Patterson, A., \& Smith, D. (2006). Policing and the Criminal Justice System - Public Confidence and Perceptions: Findings from the 2004/5 British Crime Survey. (Home Office Online Report 07/06.) London: Home Office.

Anderson, L. E., Weston, E.A., Doueck, H.J., \& Krause, D.J. (2002). The child-centered social worker and the sexually abused child: Pathway to healing. Social Work, 47(4), 368378.

Bacon, H. (2008). Cleveland 20 years on: what have we learned about intervening in child sexual abuse? Child Abuse Review, 17(4), 215-229. doi: 10.1002/car.1034

Bedfordshire Domestic \& Sexual Abuse Partnership (n.d.). Specialist Domestic Violence Court.

Retrieved

from: http://www.bedsdv.org.uk/page.asp?section $=00010001002400040009 \&$ sectionTitle $=$ Speciali $\underline{\text { st }+ \text { Domestic }+ \text { Violence }+ \text { Court }}$

Ben-Arieh, A., \& Windman, V. (2007). Secondary Victimization of Children in Israel and the Child's Perspective. International Review of Victimology, 14(3), 321-336.

Booth, T. \& Carrington, K. (2007). A comparative analysis of the victim policies across the Anglo-speaking world. In S. Walklate (ed). Handbook of Victims and Victimology. Cullompton: Willan.

Brayley, H., Cockbain, E. \& Gibson, K. (2014). Rapid evidence assessment - the sexual exploitation of boys and young men. Essex: Barnardo's. 
Casciani, D. (2013, June 11). Child victims to be given video protection. $B B C$. Retrieved from: http://www.bbc.co.uk/news/uk-22849632

Connon, G., Crooks, A., Carr, A., Dooley, B., Guerin, S., Deasy, D., O'Shea, D., Ryan, I. \& O'Flaherty, A. (2011). Child sex abuse and the Irish criminal justice system. Child Abuse Review, 20(2), 102-119. doi: 10.1002/car.1156

Cooper, P. (2011). ABE Interviews, children's testimony and hearing the voice of the child in family cases: Are we barking up the right tree? Paper presented at the Dartington Conference, Dartington Hall.

Cossar, J., Brandon, M. \& Jordan, P. (2011). 'Don't make assumptions': Children's and young people's views of the child protection system and messages for change. London: Office of the Children's Commissioner.

Cronch, L. E., Viljoen, J. L., \& Hansen, D. J. (2006). Forensic interviewing in child sexual abuse cases: Current techniques and future directions. Aggression and Violent Behavior, 11(3), 195-207. doi: 10.1016/j.avb.2005.07.009

Cross, T. P., Jones, L. M., Walsh, W. A., Simone, M., \& Kolko, D. (2007). Child forensic interviewing in Children's Advocacy Centers: empirical data on a practice model. Child Abuse \& Neglect, 31(10), 1031-1052. doi: 10.1016/j.chiabu.2007.04.007

Davidson, J., Bifulco, A., Grove-Hills, J. \& Chan, J. (2012). An Exploration of Metropolitan Police Investigative Practices with Child Victims of Sexual Abuse. London: Centre for Abuse \& Trauma Studies, Kingston University.

Davidson, J. \& Bifulco, A. (2009). Investigating police practice in the UK: Achieving best evidence in work with young victims of abuse. Pakistan Journal of Criminology, 1(3), 19-46. Davis, G., Hoyano, L., Keenan, C., Maitland, L. \& Morgan, R. (1999). The admissibility and sufficiency of evidence in child abuse in prosecutions. London: Home Office.

Davies, P. (2003). The magenta book. Guidance notes for policy evaluation and analysis. 
Chapter 2. What do we already know? London: Cabinet Office.

Devon County Council (n.d.). Child Protection: MASH. Retrieved from: http://www.devon.gov.uk/mash.htm

Forrester, D., Westlake, D., McCann, M., Thurnham, A., Shefer, G., Glynn, G. \& Killian, M. (2013). Reclaiming Social Work? An Evaluation of Systemic Units as an Approach to Delivering Children's Services: Summary report of a comparative study of practice and the factors shaping it in three local authorities. Luton: Tilda Goldberg Centre, University of Bedfordshire.

Gekoski, A., Adler, J.R. \& Gray, J.M. (2013). Interviewing women bereaved by homicide: Reports of secondary vicitmization by the Criminal Justice System. International Review of Victimology, 19, 307 - 329.

Greer, C. (2007). News Media, Victims and Crime. In P. Davies, P. Francis \& C. Greer (eds) Victims, Crime and Society. London: Sage.

Gough, D. (2007). Weight of evidence: A framework for the appraisal of the quality and relevance of evidence In J. Furlong \& A. Oancea (eds) Applied and practice based research. Special edition of Research Papers in Education, 22, 213-228.

Guðbrandsson, B. (2010). Towards a child friendly justice and support for child victims of sexual abuse. In Council of Europe Publishing (Ed.), Protecting children from sexual violence: A comprehensive approach (pp. 85-96). Strasbourg: Council of Europe.

Hayes, D., Bunting, L., Lazenbatt, A., Carr, N. \& Duffy, J. (2011). The Experiences of Young Witnesses in Criminal Proceedings in Northern Ireland. Belfast, Northern Ireland: NSPCC Northern Ireland \& Queens University Belfast.

HMCPSI \& HMIC (2012). Joint Inspection Report on the Experience of Young Victims and Witnesses in the Criminal Justice System. London: HMCPSI \& HMIC.

Home Office (July 2013). Multi-Agency Working and Information Sharing Project: Early 
Findings. London: Home Office.

Horvath, M.A.H., Alys, L., Massey, K., Pina, A., Scally, M. \& Adler, J. (2013). "Basically... porn is everywhere": A rapid evidence assessment on the effects that access and exposure to pornography has on children and young people. London: Office for the Children's Commissioner.

Jackson, S. L. (2004). A USA national survey of program services provided by child advocacy centers. Child Abuse \& Neglect, 28(4), 411-421. doi: 10.1016/j.chiabu.2003.09.020 Jensen, T. K., Gulbrandson, W., Mossige, S., Reichelt, S., \& Tjersland, O. A. (2005). Reporting possible sexual abuse: A qualitative study on children's perspectives and the context for disclosure. Child Abuse \& Neglect, 29, 1395-413.

La Rooy, D., Lamb, M. E., \& Memon, A. (2011). Forensic interviews with children in Scotland: A survey of interview practices among police. Journal of Police and Criminal Psychology, 26, 26-34.

McDonald, S. \& Tijierino, A. (2013). Male Survivors of Sexual Abuse and Assault: Their Experiences. Canada: Research and Statistics Division, Department of Justice Canada.

McNamee, H., Molyneaux, F., \& Geraghty, F. (2012). Key stakeholder evaluation of NSPCC Young Witness Service Remote Live Link (Foyle). London: NSPCC Northern Ireland.

Miller, A. \& Rubin, D. (2009). The contribution of children's advocacy centers to felony prosecutions of child sexual abuse. Child Abuse \& Neglect, 33(1), 12-18.

Mattso (Ministerial Advisory Task Team on the Adjudication of Sexual Offences Matters) (2013). Report on the Re-establishment of Sexual Offences Courts. The Department of Justice and Constitutional Development, Republic of South Africa.

Morgan, R. (2014). The children's views digest. Manchester: Ofsted.

Munro, E. (2010). The Munro review of child protection. Part one. A System's Analysis. Norwich: The Stationary Office. 
Munro, E. (2011a). The Munro review of child protection. Interim Report. The Child's Journey. Norwich: The Stationary Office.

Munro, E. (2011b). The Munro review of child protection: Final report. A child-centered system. Norwich: The Stationary Office.

NYCOURTS.GOV (n.d.). Sex Offense Courts. Retrieved from: http://www.nycourts.gov/courts/problem_solving/so/home.shtml

Ofsted, (2011). The voice of the child: Learning lessons from serious case reviews. Manchester: Ofsted.

Oliver, C. (2010). Children's views and experiences of contact with social workers: A focused review of the evidence. Leeds: Children's Workforce Development Council.

Platt, D. (2006). Investigation or Initial Assessment of Child Concerns? The Impact of the Refocusing Initiative on Social Work Practice. British Journal of Social Work, 36(2), 267281.

Plotnikoff, J. \& Woolfson, R. (2009). Measuring up? Evaluating implementation of Government commitments to young witnesses in criminal proceedings. London: NSPCC.

Plotnikoff, J. \& Woolfson, R. (2004). In their own words the experiences of 50 young witnesses in criminal proceedings. London: NSPCC.

Radford, L., Corral, S., Bradley, C., Fisher, H., Bassett, C., Howat, N., \& Collishaw, S. (2011). Child abuse and neglect in the UK today. London: NSPCC.

Prior, V., Lynch, M.A., \& Glaser, D. (1999). Responding to child sexual abuse: an evaluation of social work by children and their carers. Child and Family Social Work, 4, 131-143.

Stoltenborgh, M., IJzendoorn, M.H., Euser, E.M., \& Bakermans-Kranenburg, M.J. (2011). A Global Perspective on Child Sexual Abuse: Meta-Analysis of Prevalence Around the World, Child Maltreatment, 16(2), 79-101.

Richards, P., Morris, S., Richards, E., \& Siddall, K. (2007). On the record: Evaluating the 
Visual Recording of Joint Investigative Interviews with Children. Edinburgh: Scottish Executive Social Research

Robinson, B. (2008a). ABE Interviews: Is the Child's 'Best Evidence' being achieved in alleged sexual abuse cases? (Part 1). Family Law Week.

Robinson, B. (2008b). ABE Interviews: Is the Child's 'Best Evidence' being achieved in alleged sexual abuse cases? (Part 2). Family Law Week.

SAFLII (2013). Sexual Offenses Courts to be re-established. Retrieved from: www.saflii.org/za/journals/DEREBUS/2013/163.html

The Gatehouse Investigation Program (n.d.). The Gatehouse Investigation Program. Retrieved from: http://www.thegatehouse.org/gatehouse-investigation-program

Thomforde-Hauser, R. \& Grant, J.A. (2010). Sex Offence Courts: Supporting Victim and Community Safety Through Collaboration. Centre for Court Innovation.

Triangle (n.d). What We Do. Retrieved from: http://www.triangle.org.uk/what-we-do

Westcott, H. L. \& Kynan, S. (2004). The application of a 'storytelling' framework to investigate interviews for suspected child sexual abuse. Legal and Criminological Psychology, 9, 37-56.

Wood, J. M., \& Garven, S. (2000). How Sexual Abuse Interviews Go Astray: Implications for Prosecutors, Police, and Child Protection Services. Child Maltreatment, 5(2), 109-118. doi: $10.1177 / 1077559500005002003$

Zajac, R., O’Neill, S., \& Hayne, H. (2012). Disorder in the courtroom? Child witnesses under cross-examination. Developmental Review, 32(3), 181-204. doi: 10.1016/j.dr.2012.06.006 